\title{
How humans walk: Bout duration, steps per bout, and rest duration
}

\author{
Michael S. Orendurff, MS; ${ }^{1-2 *}$ Jason A. Schoen, BS; ${ }^{1}$ Greta C. Bernatz, BA; ${ }^{1}$ Ava D. Segal, MS; ${ }^{1}$ Glenn K. \\ Klute, PhD $^{1,3-4}$ \\ ${ }^{1}$ Motion Analysis Laboratory, Rehabilitation Research and Development Service, Department of Veterans Affairs \\ Puget Sound Health Care System, Seattle, WA; Departments of ${ }^{2}$ Rehabilitation Medicine, School of Medicine, \\ ${ }^{3}$ Mechanical Engineering, and ${ }^{4}$ Electrical Engineering, University of Washington, Seattle, WA
}

\begin{abstract}
Much is known about human walking, but it is not known how walking is used during typical activities. Since improving walking ability is a key goal in many surgical, pharmacological, and physiotherapeutic interventions, understanding typical community mobility demands regarding the length of walking bouts, the number of sequential steps frequently performed, and the duration of common nonwalking (rest) behavior seems prudent. This study documents the gait of daily living in 10 nondisabled employed adults to define walking bout duration, sequential step counts, and length of rest periods over a 2-week period. Subjects wore a StepWatch ${ }^{\mathrm{TM}}$ Activity Monitor (OrthoCare Innovations; Mountlake Terrace, Washington) that counted steps in each 10-second time window. Custom code summed sequential steps, periods of walking behavior (bouts), and periods without steps (rest). Sixty percent of all walking bouts lasted just 30 seconds or less; a 2-minute walking bout was just 1 percent of total walking bouts. Forty percent of all walking bouts were less than 12 steps in a row, and 75 percent of all walking bouts were less than 40 steps in a row. Rest periods were predominantly very short, with half of all rests periods lasting 20 seconds or less. The community mobility demand for nondisabled employed adults appears to involve frequent short-duration walking behavior with low numbers of sequential steps strung together and many shortduration nonwalking (rest) behaviors.
\end{abstract}

Key words: community mobility, duration, gait, mobility, nondisabled, rehabilitation, rest, SAM, steps, walking.

\section{INTRODUCTION}

Human gait has been the focus of a substantial number of investigations. Many have focused on joint motions [1-4], moments, and powers using two- and threedimensional inverse dynamics approaches [5-6]. Straightahead, steady-state walking across a range of speeds comprises the vast majority of nondisabled human gait studies, although work has expanded into turning [7-14], obstacle avoidance [15-18], walk-to-run transitions [1921], and even backward walking [22-23]. Human gait has been quite well described and is reasonably well understood, but there has been very limited research into how humans link steps together for functional community mobility.

In typical metropolitan settings where individuals work, recreate, shop, and commute, a particular level of mobility is necessary to meet the travel demands of daily activities within a specific community. These travel

Abbreviations: $\mathrm{SAM}=$ StepWatch $^{\mathrm{TM}}$ Activity Monitor, SD = standard deviation.

* Address all correspondence to Michael S. Orendurff, MS; Movement Science Laboratory, Texas Scottish Rite Hospital for Children, 2222 Welborn St, Dallas, TX 75219; 214-5597580. Email: michael.orendurff@tsrh.org

DOI: 10.1682/JRRD.2007.11.0197 
demands have a substantial environmental component and may be dependent upon terrain, climate, season, weather, architecture and building practices, transportation options, surface conditions, ambient lighting, or other factors. For individuals with gait disabilities to become fully integrated in the community in which they live, they must meet or exceed the functional capacity required to be mobile within their specific environment. This mobility demand has been assessed by several authors using questionnaires or surveys asking individuals to state what they would like to accomplish in the community, which activities they perform, and which activities they avoid [24-25].

The effects of an intervention should be evaluated while individuals perform the type of gait they need to achieve functional mobility, the type of gait they find especially challenging, or the type of gait that is perceived to be the most important by the individual. Most current gait outcome studies evaluate a type of gait that is simply convenient to study. For example, 92.5 percent of individuals with lower-limb amputations who use prosthetic limbs for mobility identified walking on sidewalks and streets as important to them [24]. Unfortunately, rehabilitation therapies are not always focused upon functional community ambulation activities [26] but instead focus on the types of walking possible within the therapeutic setting (hospital corridors). The long, straight hallways in many institutional and clinical settings bias gait observation and gait rehabilitation to long-duration straight walking and may not reflect the specific challenges typically encountered in the gait of daily living.

Gait velocity has been chosen by several authors as an indicator of overall functional ability [27-28], success as a community ambulator [29], or other morbidity or mortality metrics. Some researchers have focused on endurance, suggesting that individuals who are unable to walk $400 \mathrm{~m}$ at once have a greater level of disability than those individuals who can walk for this extended distance [30]. Others have used both, suggesting that speed on a $4 \mathrm{~m}$ walk test can predict success on a $400 \mathrm{~m}$ walk test for older adults [31]. Using gait velocity or gait endurance as an outcome measure in judging the efficacy of an intervention may be less useful than focusing on improving performance on more typical walking behaviors needed for successful and competent community ambulation. It is hypothesized that functional walking endurance might be best described as low-intensity interval training, with many short-duration walking bouts strung together with short rest periods. All of the tests developed by research- ers and clinicians alike are based on logical assumptions of the types of walking necessary for community ambulation and have obvious face validity but lack any strong evidence to support the assumptions.

Few authors have evaluated the relationship between self-reported problems with community ambulation and direct observational studies of selected activities that challenge walking ability. Stepien et al. [32] found that self-report of activity did not agree with activity recorded with a small ankle-mounted step counting device in amputee subjects. Shumway-Cook et al. [25] compared self-reported community mobility to direct observation of ambulation ability during frequently occurring trips into the community in elderly subjects with $(n=17)$ and without $(n=34)$ walking difficulty. The results revealed statistically significant correlations between the selfreported mobility and observed mobility, although $r$ values of the eight dimensions did not account for a large portion of the variance in either group (range of $r=-0.02$ to 0.48 represents $0.04 \%-23 \%$ of the variance in common). Some question remains as to the level of speed, endurance, maneuverability, efficiency, stability, safety, etc., of human gait that are necessary for optimal performance in the gait of daily living, and a simple description of the length of walking bouts in the gait of daily living has not yet been reported.

Accelerometer-based devices have been used by several authors to assess walking ability over several days or weeks in both household and community ambulation [33-38]. Klute et al. reported that prosthetic prescription makes no differences in the step count or step rate as recorded by the StepWatch ${ }^{\mathrm{TM}}$ Activity Monitor (SAM) (OrthoCare Innovations; Mountlake Terrace, Washington) in transfemoral and transtibial amputees who are community ambulators [38]. However, steps were summed every 1 minute over a 1-week period, leaving some doubt as to the number of sequential steps, bout duration, and rest length of typical walking activities in this patient population. The SAM has also been used to determine that older adults with gait disability take fewer steps, have shorter duration of activity, and have fewer bouts of activity than nondisabled younger adults [34].

Since gait restoration is a key objective in many surgical, pharmacological, and rehabilitation paradigms, it seems prudent to define the duration of typical walking bouts and the number of sequential steps used during gait of daily living to more clearly define walking performance characteristics during functional community ambulation. 
Therefore, the purpose of this study was to define the time length of walking bouts, the number of sequential steps, and the rest periods of employed adults in an urban environment during gait of daily living.

\section{METHODS}

Ten nondisabled adults volunteered to have their steps counted by wearing a SAM (Figure 1) every day during all waking hours for 14 days.

Step data were collected until each subject had 10 weekdays and 4 weekend days of data over a 2- to 3 -week period. Some subjects occasionally forgot to wear the SAM on a particular day and needed additional days of step counts to meet the required number of days. The specific programming chosen for this study resulted in the SAMs being completely filled with data within 8 days, and all subjects returned to the laboratory each week to have the recorded step data transferred from the SAM and the newly programmed SAM placed back on their ankle for the remainder of the needed days. The subjects were (mean \pm standard deviation [SD]) $36.3 \pm 14.8$ years of age, $167.1 \pm 10.2 \mathrm{~cm}$ in height, and $69.6 \pm 14.0 \mathrm{~kg}$ in weight. All subjects were employed in office work away

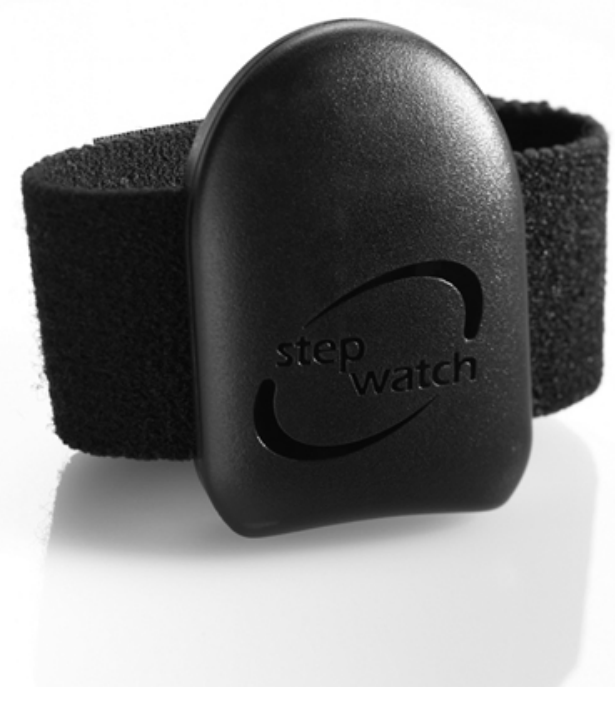

Figure 1.

The StepWatch ${ }^{\mathrm{TM}}$ Activity Monitor (OrthoCare Innovations; Mountlake Terrace, Washington). from home and worked $\sim 8$ am to $\sim 5 \mathrm{pm}$ Monday through Friday. The methods were approved by the University of Washington Institutional Review Board, and informed consent was given by each subject. A SAM was strapped to the right ankle and programmed to record all right-side steps in 10-second intervals. These monitors record an acceleration of the foot and then lock-out any additional "steps" until a period of time has passed equivalent to swing time of the subject's limb (based on subject height). SAMs have step count accuracy of better than 98 percent [39-41]. Repeated shaking of the foot is not counted as steps, since each acceleration occurs too often to be walking so the step-detection algorithm prevents recording. The SAMs will occasionally record steps during automobile or bus transit if acceleration occurs intermittently after a sufficient period of time without acceleration. Occasional foot movement during seated rest may also be counted as a step, and the method to remove these errors from the step count data is explained below.

For this study, a walking bout was defined as a period of time in which steps occurred in subsequent 10 -second intervals. A walking bout ended when no steps were detected in a 10-second window of time. Custom code in MATLAB (The MathWorks, Inc; Natick, Massachusetts) converted right foot-offs to steps, summed sequential steps and time intervals to determine the length of each walking bout (seconds) and number of steps in a row taken during each walking bout, and calculated the duration of rest bouts when no steps were taken. The following formula was used to convert SAM data:

2(Right foot-offs) \pm 1 = steps.

Therefore, a recording of 2 right foot-offs is $4 \pm 1$ steps:

Left, Right, Left, Right, Left $=2$ Right foot-offs $=5$ steps; or

Left, Right, Left, Right, or Right, Left, Right, Left = 2 Right foot-offs = 4 steps; or

Right, Left, Right $=2$ Right foot-offs $=3$ steps.

A 10-second time interval in which only a single right foot-off (a singleton) was recorded without subsequent or prior steps within the adjacent 10 -second time windows was considered an error. These were not considered steps since any foot movement after a period of quiet would elicit this recording (leg crossing, for example), and all singletons were removed from the analysis. Therefore, two right foot-offs ( $4 \pm 1$ steps) were considered the lowest step count that was valid. Single right foot-offs were 
considered steps if they preceded or followed another 10second bout in which steps were recorded. A demonstration of the SAM output and the resulting step-count code is shown in Figure 2.

The step data, walking bout duration data, and rest bout duration data were plotted as frequency histograms to determine the number of sequential steps taken before stopping, the duration of walking bouts, and the duration of rest bouts. The goal of this study was to describe the average walking bout characteristics of the gait of daily living for nondisabled employed adults. Results for each individual are also shown.

\section{RESULTS}

Overwhelmingly, subjects walked short-duration bouts with low numbers of steps in a row. Cumulative data for all subjects showed that walking up to $12 \pm 1$ steps in a row accounted for 40 percent of all walking bouts (Figure 3). This was true for the individual with

\begin{tabular}{|c|c|c|c|}
\hline \multicolumn{2}{|c|}{ Typical StepWatch ${ }^{\mathrm{TM}}$ Output } & \multicolumn{2}{|c|}{ Results of MATLAB Code } \\
\hline R Foot-Offs & Time (s) & Steps & Rest \\
\hline $\begin{array}{l}0 \\
0\end{array}$ & $\begin{array}{l}10 \\
10\end{array}$ & & Rest $20 \mathrm{~s}$ \\
\hline 2 & 10 & & \\
\hline $\begin{array}{r}11 \\
4\end{array}$ & $\begin{array}{l}10 \\
10\end{array}$ & 34 steps in $30 \mathrm{~s}$ & \\
\hline $\overrightarrow{0}$ & 10 & & \\
\hline 0 & 10 & & \\
\hline 1 & 10 & (Step deleted) & Rest $50 \mathrm{~s}$ \\
\hline 0 & 10 & & \\
\hline 0 & 10 & & \\
\hline 1 & 10 & & \\
\hline 9 & 10 & & \\
\hline 11 & 10 & 60 steps in $50 \mathrm{~s}$ & \\
\hline 8 & 10 & & \\
\hline 1 & 10 & & \\
\hline 0 & 10 & & \\
\hline 0 & 10 & & Rect 40 s \\
\hline 0 & 10 & & Rest $40 \mathrm{~s}$ \\
\hline 0 & 10 & & \\
\hline 2 & 10 & & \\
\hline 12 & 10 & & \\
\hline 10 & 10 & 82 steps in $50 \mathrm{~s}$ & \\
\hline 11 & 10 & & \\
\hline 6 & 10 & & \\
\hline 0 & 10 & & Rest $10 \mathrm{~s}$ \\
\hline
\end{tabular}

Figure 2.

StepWatch ${ }^{\mathrm{TM}}$ Activity Monitor (SAM) output with the results of the custom MATLAB (The MathWorks, Inc; Natick, Massachusetts) code showing right (R) foot-offs recorded in each 10 -second window, the summed sequential steps calculated, the walking bout duration, the rest periods, and the removal of an erroneous "singleton" from the data. Steps calculated from SAM data are \pm 1 step in all cases. the most walking bouts (subject 3 ) and for the individual with the least walking bouts (subject 6).

Seventeen percent of bouts were just $4 \pm 1$ steps in a row, and 75 percent of all bouts were less than $40 \pm 1$ steps in a row. Each subject had periods of walking with high numbers of steps in a row, but these walking bouts occurred very infrequently. These infrequently occurring walking bouts with high numbers of steps in a row are summarized in Table 1 as a percentage of walking bouts and total steps. The data represented in Figure 3 are summarized in the first row of Table 1 and show that 4 to 99 steps in a row was 90.48 percent of all walking bouts and accounted for 37.03 percent of total steps taken. Walking bouts that lasted 100 to 199 steps in a row were 5.61 percent of all walking bouts, and comprised 14.19 percent of all steps taken. Walking bouts of 400 to 499 steps in a row were 0.46 percent of all walking bouts and accounted for 3.83 percent of all steps. Very long-duration walking behavior (3,000-10,000 steps in a row) was extremely rare, just 0.14 percent of all walking bouts, but because of their long duration, accounted for 12.38 percent of the total number of steps taken. This was the case for subject 3 , who had the most long-duration bouts, but since this subject also had the most steps, these long-duration walking bouts remained extremely rare events; there were only 33 walking bouts longer than 1,000 steps in a row out of a total of 5,862 bouts. The 33 long-duration bouts equal less than 0.56 percent of all bouts. All subjects' data are shown in Figure 4 with bout number plotted against steps in a row. Each subject's steps in a row frequency distribution is shown in Figure 5, and every subject showed a similar gamma distribution (Figure 5 inset).

When subjects began walking, 20.1 percent of the time they stopped in 10 seconds or less and 26 percent of the time they stopped within 10 to 20 seconds; these 20 -second walking bouts were the most frequently occurring walking bout duration. Therefore, 60 percent of all walking bouts lasted less than 30 seconds, and 81 percent of all walking bouts lasted 1 minute or less (Figure 6).

A 2-minute walking bout was just 1 percent of all walking bouts. Table 2 shows the long-duration bouts that occur very infrequently; for example, all walking bouts lasting 200 to 299 seconds comprised 1.58 percent of all walking bouts and accounted for 7.21 percent of total bout time. Walking bouts that lasted 1,000 to 1,999 seconds comprised 0.22 percent of all walking bouts, but because of their long duration, accounted for 5.79 percent of total bout time. The data from Figure 6 are summarized in the first row of Table 2 and show 


\section{$40 \%$ of all bouts were less than $12 \pm 1$ steps in a row}

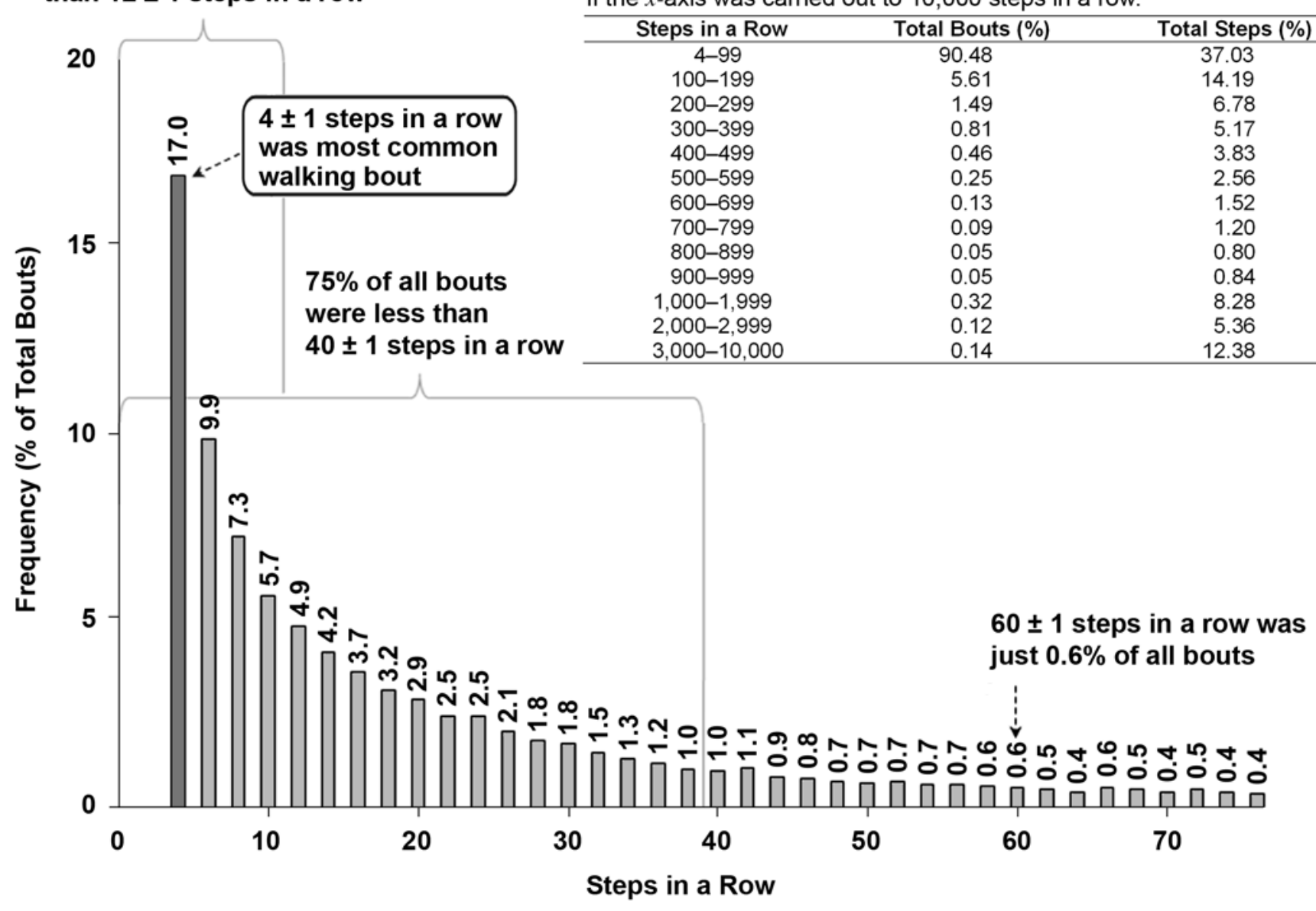
table demonstrates that very few walking bouts with high numbers of steps in a row were observed. These data would appear in Figure 3 if the $x$-axis was carried out to 10,000 steps in a row.

\begin{tabular}{ccc}
\hline Steps in a Row & Total Bouts (\%) & Total Steps (\%) \\
\hline $4-99$ & 90.48 & 37.03 \\
$100-199$ & 5.61 & 14.19 \\
$200-299$ & 1.49 & 6.78 \\
$300-399$ & 0.81 & 5.17 \\
$400-499$ & 0.46 & 3.83 \\
$500-599$ & 0.25 & 2.56 \\
$600-699$ & 0.13 & 1.52 \\
$700-799$ & 0.09 & 1.20 \\
$800-899$ & 0.05 & 0.80 \\
$900-999$ & 0.05 & 0.84 \\
$1,000-1,999$ & 0.32 & 8.28 \\
$2,000-2,999$ & 0.12 & 5.36 \\
$3,000-10,000$ & 0.14 & 12.38 \\
\hline
\end{tabular}

Table 1. Larger number step counts (to 10,000 steps in a row) as a percentage of total bouts and as a percentage of total steps. This

Figure 3.

Cumulative sequential steps for all subjects: the number of steps in a row plotted against the frequency (how frequently a particular number of steps in a row occurred) as a percentage of the total number of bouts. Each bar represents a number of steps in a row, and the number above indicates the percentage of the total walking bouts. A bout of walking is defined as the period of time when 4 or more steps are strung together in one or multiple 10 -second windows. Each datum is \pm 1 step. This graph represents how many steps are generally taken in a row before stopping. The percentages are summed within the brackets; for example, $75 \%$ equals the sum of the 18 different percentages within this bracket. Since long walking bouts with high numbers of steps in a row are extremely infrequent, the graph only covers from $4 \pm 1$ steps in a row to $76 \pm 1$ steps in a row. Table 1 shows the distribution of the less frequent walking bout durations as a percentage of total bouts and total steps.

that 97.08 percent of all walking bouts lasted less than 200 seconds and accounted for 72.77 percent of total bout time. Each individual has a similar distribution of bout-duration frequency (Figure 5). The most common walking bout duration for each individual was 20 seconds; 10 -second bouts were the next most common, and each subject had a similar gamma distribution in their bout-duration frequency plots (Figure 5 inset).

Rest periods (time with no recorded walking behavior) of 20 seconds or less accounted for half of all rest periods
(Figure 7). Seventy-five percent of all rest periods were 70 seconds or less, and 87 percent of all rest periods were 3 minutes or less. A 10 -second rest was the most frequently occurring rest period, comprising 33.1 percent of all rests. Table 3 summarizes the longer duration rest periods; the data from Figure 7 are displayed in the first row of Table 3.

These data show that long rests, lasting between 5,000 and 50,000 seconds (1.4-13.8 hours) are just 0.43 percent of the total number of rest bouts, but because of their long duration, account for 46.49 percent of the total 


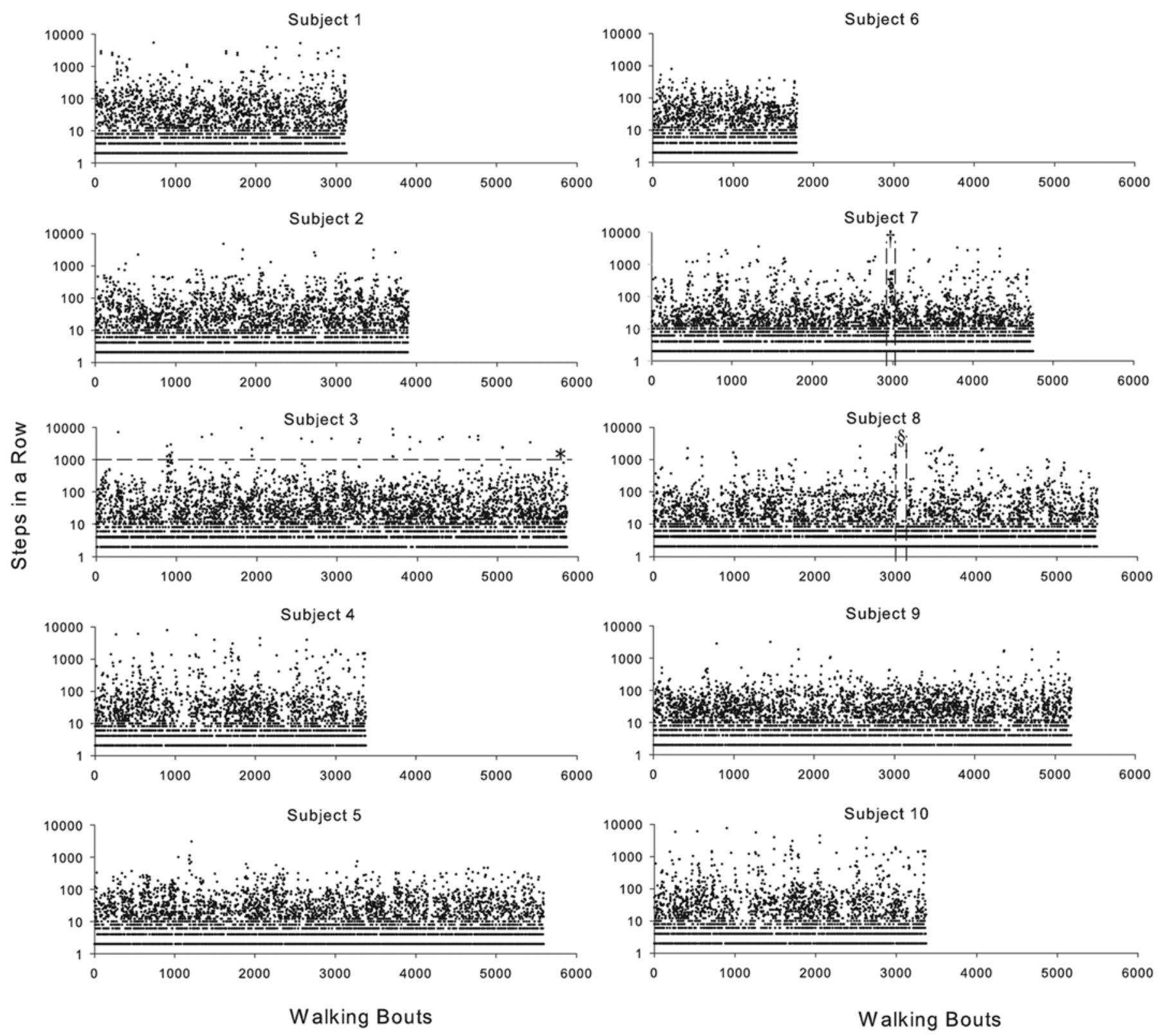

Figure 4.

Individual subject data: walking bouts plotted against the number of steps in a row (log scale). For each subject, the data cover 14 days but not necessarily consecutive days. The data are primarily clustered around short-duration walking regardless of whether subjects walked many bouts (subject 3) or few bouts (subject 6). Subject 3 had dozens of long-duration walking bouts above 1,000 steps in a row (*) but had very similar short-duration bout distribution compared with subject 6 (see Figure 5). Subject 4 did not accrue a large number of walking bouts but had many long-duration bouts above 1,000 steps in a row. This is in contrast to subject 9 who had many more walking bouts but very few that lasted longer than 1,000 steps in a row. No distinction between weekends and weekdays is obvious from these data, even though each subject had a 2-day weekend every 5 days. The lowest row of data for each subject (singleton-2 steps) was judged to be an error and removed from the analysis (see "Methods" in main text). Near bout 3,000, subject 7 went hiking $(\dagger)$, producing many long-duration walking bouts and only a very few shortduration walking bouts. Near bout 3,000, subject 8 (§) had no long-duration bouts and only a few very short-duration walking bouts, perhaps choosing to watch television instead. 

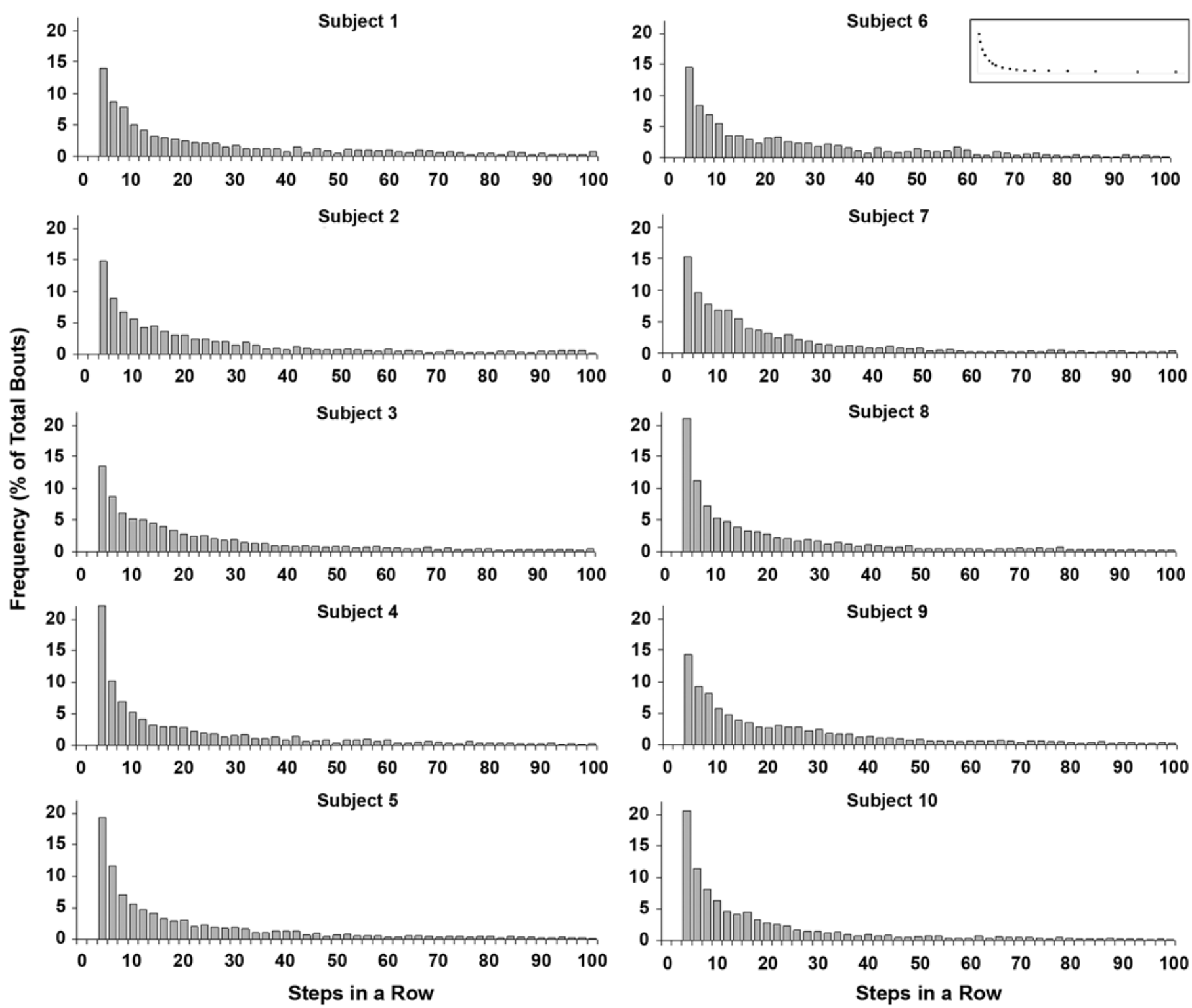

Figure 5.

Individual subject sequential step data: steps in a row as a percentage of total walking bouts. Each subject has similar distributions, with $4 \pm 1$ steps in a row the most frequently occurring number of steps in a row; this was between $14 \%$ and $22 \%$ of the subjects' total walking bouts. Note that subject $6(\sim 1,800$ total walking bouts) and subject 8 ( 5,800 total walking bouts) have nearly identical frequency distributions. Inset is an example of a gamma distribution, which best describes the subjects' individual walking bout data.

rest time. One hundred and forty of these long rests (10 subjects $\times 14$ days) were judged to be sleep since they occurred late in the evening and lasted longer than 6 hours. Rests lasting 1,000 to 1,999 seconds (17-33 minutes) were just 1.63 percent of all rests but accounted for 10.36 percent of total rest time. Shorter rests, those lasting 400 to 499 seconds, accounted for almost the same percentage of the total rest bouts, but because of their shorter duration, accounted for just 2.96 percent of the total rest time.

Between-subject variability is difficult to estimate in a meaningful way due to the gamma distribution of these data. Since the data do not fall into a standard bell curve, the mean and SD do not adequately describe the central tendency of the data due to very infrequent data at the 


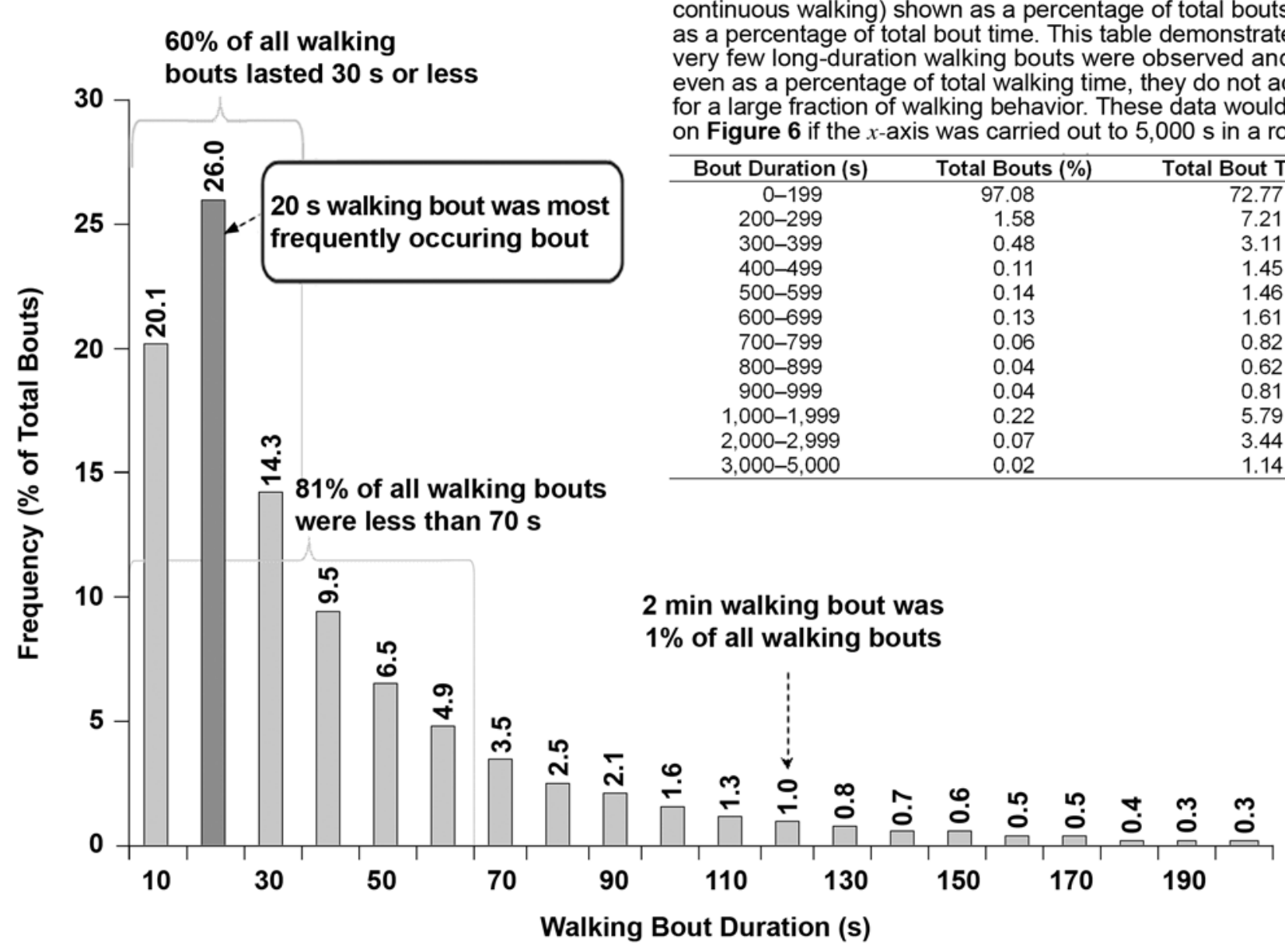

Figure 6.

Cumulative walking bout duration for all subjects: the length of time subjects strung together sequential steps before stopping. Walking bout duration is plotted against frequency (the number of occasions a particular walking bout duration was observed as a percentage of total walking bouts). The bars represent each walking bout duration and the number above is the percentage of total walking bouts. The percentages are summed within the brackets; for example, walking bouts of 20 , 30, and $40 \mathrm{~s}$ account for $20.1 \%+26.0 \%+14.3 \%=60.4 \%$ of all walking bouts. Dashed arrows identify individual walking bout durations. This figure describes walking bouts that last 10 to $200 \mathrm{~s}$ and account for $97.08 \%$ of total walking bouts and $72.77 \%$ of total walking bout time. Table 2 summarizes the infrequent but long-duration walking bouts as a percentage of total walking bouts and as a percentage of total bout time. Data from Figure 6 occupy the first row of Table 2.

extreme right of the distributions. Therefore, each subject's step count data was included in Figure 4 to demonstrate individual subject's differences, with walking bout number from the first bout to the last bout over the 14 days plotted against the number of steps in a row recorded during each bout.

Subjects generally appear to have very similar distributions in short-duration walking bouts, even if they occasionally took several thousand steps in a row and accumulated nearly 5,800 walking bouts in the 14 days (subject 3) or if they walked fewer than 1,800 total steps and never had long-duration walking behavior (subject 6). Subject 3 was responsible for a large portion of the longest walking bouts but had similar distributions in the frequently occurring short-duration walking bouts as all other subjects (Figures $\mathbf{5}$ and $\mathbf{8}$ ).

\section{DISCUSSION}

Walking appears predominantly composed of just a few steps in a row over very short time frames in nondisabled 


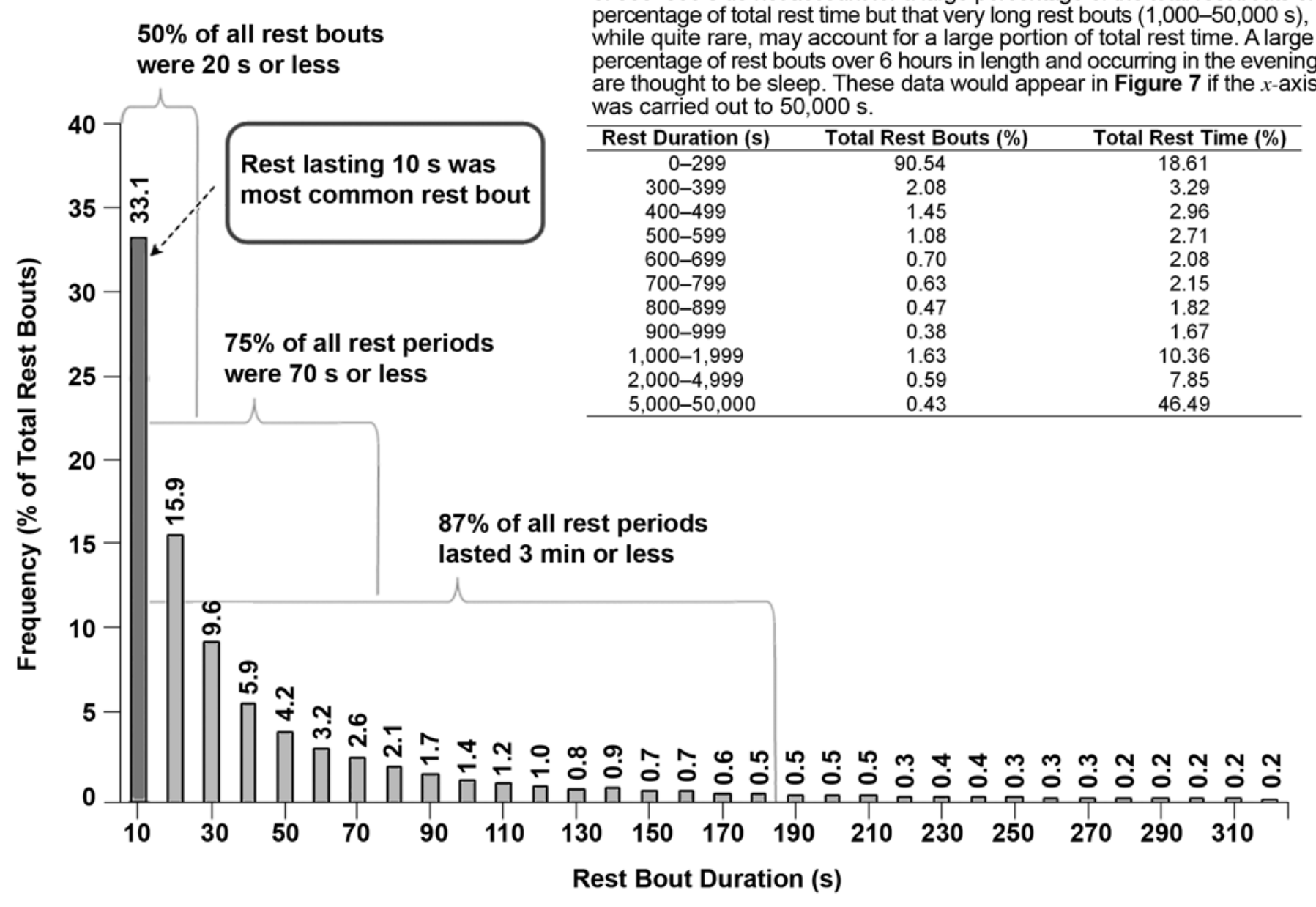

Figure 7.

Cumulative rest bout duration for all subjects: the length of time resting plotted against frequency (the number of occasions a particular rest duration was observed as a percentage of total rest bouts). Nonwalking behavior is defined as rest. Rest lasting $10 \mathrm{~s}$ (dashed arrow) was the most commonly occurring rest bout, accounting for $33.1 \%$ of all rest bouts. The percentages are summed within the brackets; for example, $75 \%$ equals the sum of all rest duration percentages within this bracket. These data show that during typical community walking, rests occur frequently and are predominantly short. Table 3 summarizes the infrequent but long-duration rest bouts as a percentage of total rest bouts and as a percentage of total rest time. Data from Figure 7 occupy the first row of Table 3.

adults participating in typical activities. Rest periods (without steps) appear frequent and very short; there are occasional long rest periods, but these occur less often and, excluding sleep, do not add up to as much total time as the many very short rests. Very long walking behavior with hundreds of steps in a row does not appear to occur very often and does not account for a large percentage of the steps taken during the day. This suggests that gait initiation, gait speed modulation, and gait termination are extremely important functional tasks for community mobility and that long-duration walking behavior is less frequently used. In addition, many of these steps likely involve turning and negotiating obstacles, especially the short-duration, low sequential-step bouts. Sedgeman et al. [42] have shown that turning steps comprise 20 percent of all steps in household settings, and Glaister et al. [9] have shown that turning steps comprise 35 to 50 percent of indoor steps during typical activities. Research has shown that turning is performed at slower speeds than walking straight [11] and that individuals tend to slow when passing 

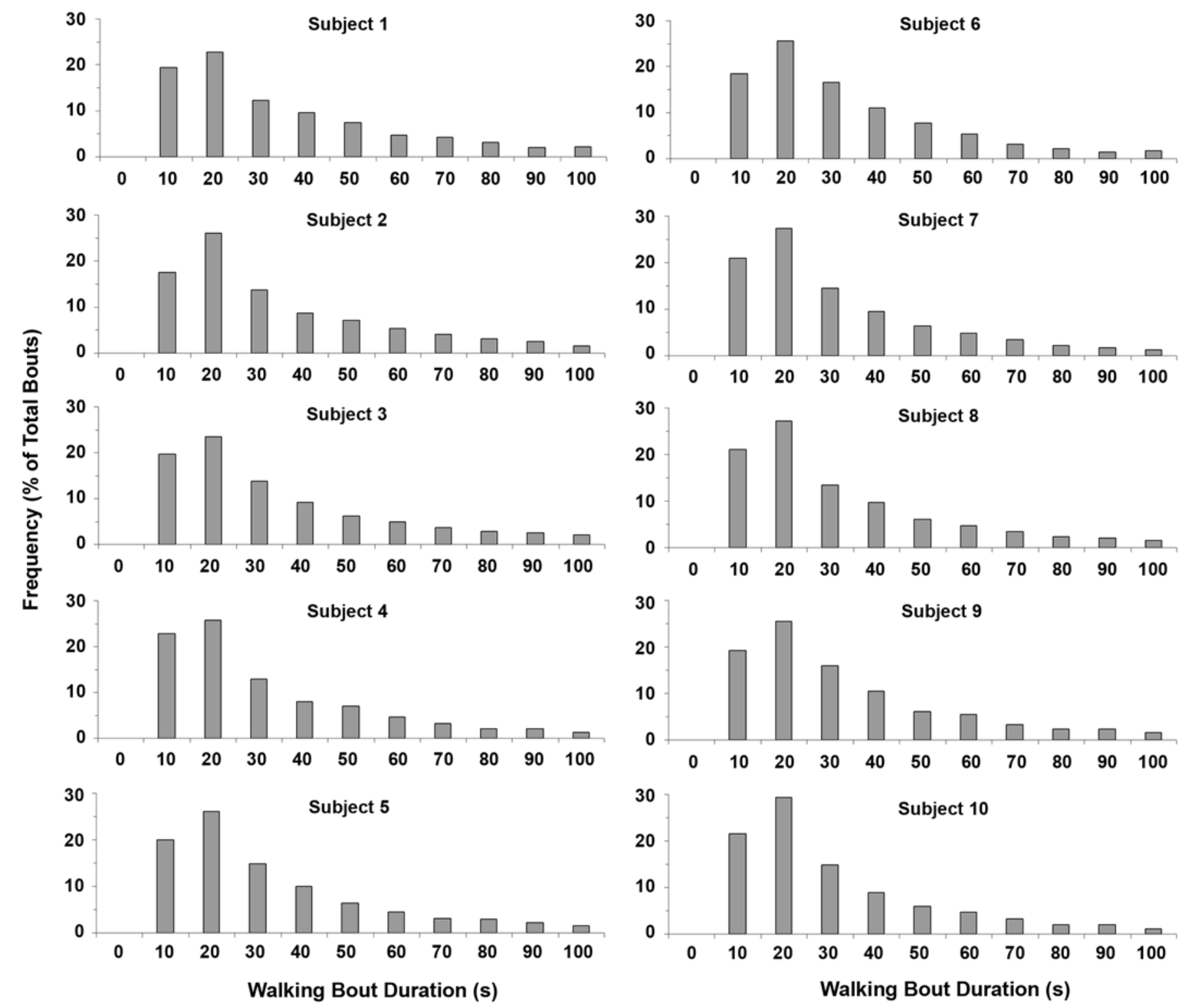

Figure 8.

Individual subject walking bout duration frequency data for each subject. These histograms show how often rest of a particular duration occurred. For each subject, walking bouts of 20 seconds were the most common walking bout length; 10 second walking bouts were the next most frequent. Subject 3 had more than 3 times the total number of walking bouts of subject 6, but both subjects had similar walking bout duration frequency distributions.

close to stationary objects and when moving objects approach them [43].

The data from this study suggest that gait initiation, increasing walking speed, decreasing walking speed, turning, and gait termination are much more frequent events than steady-state walking at the subject's selfselected walking speed. Altering walking speed and turning corners may comprise a large portion of the challenges of typical community ambulation, although these may not be the most difficult gait challenges. It is also likely that these aspects of gait-speed modulation and turn negotiation-are not analyzed with as much detail during visual observation of gait in clinic settings, during self-reported assessments of walking ability, or even 
during computerized gait analysis. Functional community ambulation is likely best described as low-intensity interval training with many stops and starts, beginning and ending with either seated posture or standing. Individual subjects generally had one to two longer walking bouts each day, usually once in the morning before work and once in the afternoon after work, thought to be associated with walking from their commuting transportation (car or bus) to their work location in the morning and back again in the afternoon. This is consistent with the data of Klute et al., which showed that individuals with transtibial amputation and individuals with transfemoral amputations walked 10 minutes in a row just once a day on average [38]. For this study, subject 3 was the exception and generally twice each day had bouts of walking with more than 2,000 steps in a row before stopping (Figure 4). This is likely not functional ambulation but rather walking for exercise, valuable in its own right, but probably not specifically necessary for mobility within the community except to maintain musculoskeletal strength and cardiovascular endurance.

It is attractive to speculate that these subjects were sedentary, but this group was in fact very active, participating in walking for fitness, soccer, bicycling, sailing, and hiking. During the 14-day period, the subjects exhibited 363 walking bouts with greater than 500 steps in a row out of a total of 43,914 walking bouts (0.82\%). Combined, these long-duration bouts were 558,766 steps, 33 percent of the 1,717,730 total steps taken by all subjects in the 14-day period. Subject 3, with the most walking bouts, most steps, and the largest number of long-duration walking bouts was not the fittest individual. ${ }^{*}$ A clear definition of "active" is needed before step counts can be used to classify individuals.

\section{CONCLUSIONS}

The data from this study suggest that short-duration walking bouts with frequent short rests comprise the community mobility demand for working adults. Very little is known about how current interventions affect an individual's performance on these more frequently occurring, short-duration community walking tasks. Perhaps surgical, pharmacological, or physiotherapeutic interven-

\footnotetext{
*Michael S. Orendurff. Unpublished data, 2008.
}

tions might have greater functional impact if they evolve to focus on these more common everyday tasks of walking, the gait of daily living. Based on the data from this study, these gaits of daily living likely involve gait initiation, speed modulation, turning to negotiate curving paths, and gait termination bracketed by standing or seated postures. Gaits of daily living probably involve short bouts of walking with a short number of steps in a row, with maneuverability and stability more important to successful community mobility than walking fast, walking for long periods, or achieving an energy-efficient self-selected walking speed. Therefore, it is likely that most mobility-related goals should focus on multiple short-duration walking bouts with stability and maneuverability emphasized. Gait endurance during walk-rest interval movements may still be vitally important, but longer duration walking does not appear to be a primary community mobility demand.

\section{ACKNOWLEDGMENTS}

This material was based on work supported by the Department of Veterans Affairs (grant A3611 I).

The authors have declared that no competing interests exist.

\section{REFERENCES}

1. Saunders JB, Inman VT, Eberhart HD. The major determinants in normal and pathological gait. J Bone Joint Surg Am. 1953;35-A(3):543-58. [PMID: 13069544]

2. Murray MP, Drought AB, Kory RC. Walking patterns of normal men. J Bone Joint Surg Am. 1964;46:335-60. [PMID: 14129683]

3. Murray MP, Kory RC, Sepic SB. Walking patterns of normal women. Arch Phys Med Rehabil. 1970;51(11):637-50. [PMID: 5501933]

4. Hughes J, Jacobs N. Normal human locomotion. Prosthet Orthot Int. 1979;3(1):4-12. [PMID: 471705]

5. Kadaba MP, Ramakrishnan HK, Wootten ME, Gainey J, Gorton G, Cochran GV. Repeatability of kinematic, kinetic, and electromyographic data in normal adult gait. J Orthop Res. 1989;7(6):849-60. [PMID: 2795325]

6. Kadaba MP, Ramakrishnan HK, Wootten ME. Measurement of lower extremity kinematics during level walking. J Orthop Res. 1990;8(3):383-92. [PMID: 2324857] 
7. Courtine G, Schieppati M. Human walking along a curved path. II. Gait features and EMG patterns. Eur J Neurosci. 2003;18(1):191-205. [PMID: 12859352]

8. Courtine G, Schieppati M. Human walking along a curved path. I. Body trajectory, segment orientation and the effect of vision. Eur J Neurosci. 2003;18(1):177-90. [PMID: 12859351]

9. Glaister BC, Bernatz GC, Klute GK, Orendurff MS. Video task analysis of turning during activities of daily living. Gait Posture. 2007;25(2):289-94. [PMID: 16730441]

10. Huxham F, Gong J, Baker R, Morris M, Iansek R. Defining spatial parameters for non-linear walking. Gait Posture. 2006;23(2):159-63. [PMID: 16399511]

11. Orendurff MS, Segal AD, Berge JS, Flick KC, Spanier D, Klute GK. The kinematics and kinetics of turning: Limb asymmetries associated with walking a circular path. Gait Posture. 2006;23(1):106-11. [PMID: 16311202]

12. Taylor MJ, Dabnichki P, Strike SC. A three-dimensional biomechanical comparison between turning strategies during the stance phase of walking. Hum Mov Sci. 2005;24(4): 558-73. [PMID: 16129503]

13. Thigpen MT, Light KE, Creel GL, Flynn SM. Turning difficulty characteristics of adults aged 65 years or older. Phys Ther. 2000;80(12):1174-87. [PMID: 11087304]

14. Xu D, Carlton LG, Rosengren KS. Anticipatory postural adjustments for altering direction during walking. J Mot Behav. 2004;36(3):316-26. [PMID: 15262627]

15. Cumming RG, Klineberg RJ. Fall frequency and characteristics and the risk of hip fractures. J Am Geriatr Soc. 1994; 42(7):774-78. [PMID: 8014355]

16. Cwikel J, Fried AV, Galinsky D, Ring H. Gait and activity in the elderly: Implications for community falls-prevention and treatment programmes. Disabil Rehabil. 1995;17(6): 277-80. [PMID: 7579477]

17. Kerrigan DC, Lee LW, Nieto TJ, Markman JD, Collins JJ, Riley PO. Kinetic alterations independent of walking speed in elderly fallers. Arch Phys Med Rehabil. 2000;81(6): 730-35. [PMID: 10857514]

18. Topper AK, Maki BE, Holliday PJ. Are activity-based assessments of balance and gait in the elderly predictive of risk of falling and/or type of fall? J Am Geriatr Soc. 1993; 41(5):479-87. [PMID: 8486878]

19. Hreljac A. Preferred and energetically optimal gait transition speeds in human locomotion. Med Sci Sports Exerc. 1993;25(10):1158-62. [PMID: 8231761]

20. Hreljac A. Determinants of the gait transition speed during human locomotion: Kinematic factors. J Biomech. 1995; 28(6):669-77. [PMID: 7601866]

21. Hreljac A, Imamura R, Escamilla RF, Edwards WB. Effects of changing protocol, grade, and direction on the preferred gait transition speed during human locomotion. Gait Posture. 2007;25(3):419-24. [PMID: 16793272]
22. Carpenter MG, Bellos A, Patla AE. Is backward stepping over obstacles achieved through a simple temporal reversal of forward stepping? Int J Neurosci. 1998;93(3-4):189-96. [PMID: 9639236]

23. Yang YR, Yen JG, Wang RY, Yen LL, Lieu FK. Gait outcomes after additional backward walking training in patients with stroke: A randomized controlled trial. Clin Rehabil. 2005;19(3):264-73. [PMID: 15859527]

24. Legro MW, Reiber G, Del Aguila M, Ajax MJ, Boone DA, Larsen JA, Smith DG, Sangeorzan B. Issues of importance reported by persons with lower limb amputations and prostheses. J Rehabil Res Dev. 1999;36(3):155-63. [PMID: 10659798]

25. Shumway-Cook A, Patla A, Stewart AL, Ferrucci L, Ciol MA, Guralnik JM. Assessing environmentally determined mobility disability: Self-report versus observed community mobility. J Am Geriatr Soc. 2005;53(4):700-704. [PMID: 15817020]

26. Latham NK, Jette DU, Slavin M, Richards LG, Procino A, Smout RJ, Horn SD. Physical therapy during stroke rehabilitation for people with different walking abilities. Arch Phys Med Rehabil. 2005;86(12 Suppl 2):S41-S50. [PMID: 16373139]

27. De Quervain IA, Simon SR, Leurgans S, Pease WS, McAllister D. Gait pattern in the early recovery period after stroke. J Bone Joint Surg Am. 1996;78(10):1506-14. [PMID: 8876578]

28. Shumway-Cook A, Guralnik JM, Phillips CL, Coppin AK, Ciol MA, Bandinelli S, Ferrucci L. Age-associated declines in complex walking task performance: The Walking InCHIANTI toolkit. J Am Geriatr Soc. 2007;55(1):58-65. [PMID: 17233686]

29. Lord SE, McPherson K, McNaughton HK, Rochester L, Weatherall M. Community ambulation after stroke: How important and obtainable is it and what measures appear predictive? Arch Phys Med Rehabil. 2004;85(2):234-39. [PMID: 14966707]

30. Gill TM, Allore HG, Hardy SE, Guo Z. The dynamic nature of mobility disability in older persons. J Am Geriatr Soc. 2006;54(2):248-54. [PMID: 16460375]

31. Rolland YM, Cesari M, Miller ME, Penninx BW, Atkinson $\mathrm{HH}$, Pahor M. Reliability of the 400-m usual-pace walk test as an assessment of mobility limitation in older adults. J Am Geriatr Soc. 2004;52(6):972-76. [PMID: 15161464]

32. Stepien JM, Cavenett S, Taylor L, Crotty M. Activity levels among lower-limb amputees: Self-report versus step activity monitor. Arch Phys Med Rehabil. 2007;88(7):896-900. [PMID: 17601471]

33. Bjornson KF, Belza B, Kartin D, Logsdon R, McLaughlin JF. Ambulatory physical activity performance in youth with cerebral palsy and youth who are developing typically. Phys Ther. 2007;87(3):248-60. [PMID: 17244693] 
34. Cavanaugh JT, Coleman KL, Gaines JM, Laing L, Morey MC. Using step activity monitoring to characterize ambulatory activity in community-dwelling older adults. J Am Geriatr Soc. 2007;55(1):120-24. [PMID: 17233695] Erratum in: J Am Geriatr Soc. 2007;55(1):125.

35. Song KM, Bjornson KF, Cappello T, Coleman K. Use of the StepWatch activity monitor for characterization of normal activity levels of children. J Pediatr Orthop. 2006; 26(2):245-49. [PMID: 16557143]

36. Karabulut M, Crouter SE, Bassett DR Jr. Comparison of two waist-mounted and two ankle-mounted electronic pedometers. Eur J Appl Physiol. 2005;95(4):335-43. [PMID: 16132120] Erratum in: Eur J Appl Physiol. 2006; 96(3):334-35.

37. McDonald CM, Widman L, Abresch RT, Walsh SA, Walsh DD. Utility of a step activity monitor for the measurement of daily ambulatory activity in children. Arch Phys Med Rehabil. 2005;86(4):793-801. [PMID: 15827934]

38. Klute GK, Berge JS, Orendurff MS, Williams RM, Czerniecki JM. Prosthetic intervention effects on activity of lower-extremity amputees. Arch Phys Med Rehabil. 2006; 87(5):717-22. [PMID: 16635636]

39. Foster RC, Lanningham-Foster LM, Manohar C, McCrady SK, Nysse LJ, Kaufman KR, Padgett DJ, Levine JA. Preci- sion and accuracy of an ankle-worn accelerometer-based pedometer in step counting and energy expenditure. Prev Med. 2005;41(3-4):778-83. [PMID: 16125760]

40. Macko RF, Haeuber E, Shaughnessy M, Coleman KL, Boone DA, Smith GV, Silver KH. Microprocessor-based ambulatory activity monitoring in stroke patients. Med Sci Sports Exerc. 2002;34(3):394-99. [PMID: 11880800]

41. Resnick B, Nahm ES, Orwig D, Zimmerman SS, Magaziner J. Measurement of activity in older adults: Reliability and validity of the Step Activity Monitor. J Nurs Meas. 2001;9(3):275-90. [PMID: 11881269]

42. Sedgeman R, Goldie P, Iansek R. Development of a measure of turning during walking. In: Advancing Rehabilitation Conference Proceedings; 1994; La Trobe University, Melbourne (Australia). p. 26-31.

43. Gérin-Lajoie M, Richards CL, McFadyen BJ. The negotiation of stationary and moving obstructions during walking: Anticipatory locomotor adaptations and preservation of personal space. Motor Control. 2005;9(3):242-69. [PMID: 16239715]

Submitted for publication November 27, 2007. Accepted in revised form April 4, 2008. 